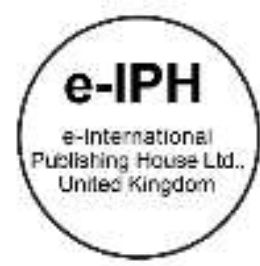

\title{
Impact of Boundary Removal Project on Residents' Perceptions: Cases in Taiwan
}

\author{
Heng Zhang, Yu-Hao Ou, Yu-Min Chang \\ Department of Architecture, \\ National Cheng Kung University, Taiwan \\ :changlin@mail.ncku.edu.tw, ddp982811@gmail.com, c25678822@gmail.com \\ Tel: +886-917-798-255
}

\begin{abstract}
Boundary removal project (BRP) aims to eliminate barriers between two sites and activate the grey residual space in-between. School campus in Taiwan is often surrounded by walls, which blocks its connection to communities and often creates security concerns. School campus has become the most popular target for BRP, which tries to turn it into a functional and aesthetic space. This study intends to explore the impact of campus BRP within a community, especially its relationships with neighborhood safety, perceived change and place attachment. The result shows that the improvement of boundary environment has a significant impact on all three perceptions.
\end{abstract}

Keywords: Environmental amelioration; Neighborhood safety; Perceived change; Place attachment

eISSN: 2398-4287 @ 2018. The Authors. Published for AMER ABRA cE-Bs by e-International Publishing House, Ltd., UK. This is an open access article under the CC BYNC-ND license (http://creativecommons.org/licenses/by-nc-nd/4.0/). Peer-review under responsibility of AMER (Association of Malaysian Environment-Behaviour Researchers), ABRA (Association of Behavioural Researchers on Asians) and cE-Bs (Centre for Environment-Behaviour Studies), Faculty of Architecture, Planning \& Surveying, Universiti Teknologi MARA, Malaysia.

https://doi.org/10.21834/e-bpj.v3i9.1532

\subsection{Introduction}

As the society changes, the school campus is no longer an enclosed learning environment, but a popular field of activity. The primary school campus, in particular, has a close connection to community life. The space that lies between the campus and the community is not merely a transition space, but also a place where the two interact and guard against each other. In the past, the principle of site planning in Taiwan was to enclose individual sites with walls. Planning and design were conducted in isolation within the walls. This planning approach often results in grey residual space between two adjacent sites, which is neither functional nor safe. The purpose of "Boundary removal project" is to remove the walls and activate the grey residual space between the two sites to turn it into a functional and aesthetic space. Campus boundary space makes up the transition space between the community and the school. However, through environmental transformation, including the use of open walls as well as greening and beautifying the walls could blur this boundary. Therefore, this study intends to explore the impact of campus boundary amelioration within a community, especially its relationships with neighborhood safety, perceived change and place attachment.

\subsection{Literature Review}

\subsection{Boundary removal project (BRP)}

The difference between boundary removal project (BRP) and general space amelioration is that BRP only ameliorates the adjacent space between two sites, and there is no need to rectify the original spatial structure. This type of space amelioration method reduces cost (Dober, 2000), and the amelioration efforts tend to focus on landscape and traffic circulation. 
The removal of boundary space mainly targets landscape renovation that improves visual qualities. The visual elements include manmade elements and ecological resources (Daniel \& Vining, 1983; Saeidi, Mohammadzadeh, Salmanmahiny, \& Mirkarimi, 2017). In addition, a school campus also serves transportation, education, communication, and recreational functions, and it should integrate ecological, cultural and local characteristics with individuality (Ruihai \& Dinghai, 2017). Outdoor space, street furniture, manmade objects, plants, sidewalks and buildings (Lynch \& Hack, 1984; Zhang \&Lin, 2011) are regarded as environmental stimulus for the residents. In terms of campus landscape, lawns, trees, colors, planting density, sculpture, ponds, and fountains, etc. will affect people's perception (Lau, Gou, \& Liu, 2014). Elements in the public space that provide comforts include leisure space, street furniture, proper sidewalk scale, planting, shading, and manmade objects (Mehta, 2014; Sullivan, Kuo, \& Depooter, 2004).

According to the above-referenced literature and characteristics of the subject site, this study divides the spatial BRP factors into six elements: "directional system and public art", "planting", "outdoor furniture", "sidewalk", "lighting facilities" and "fence or hedge".

\subsection{Relationships among BRP, perceived change, neighborhood safety, and place attachment}

There is a significant relationship between the architectural environment and people's sense of safety (Wood et al., 2008; Omar, Omar, \& Yusoff, 2016). In safe and densely populated areas, residents will be more likely to choose walking as the main means of transportation (Hong \& Chen, 2014). Environmental risk factors such as road design to be a negative influence on pedestrian safety and these risk factors increase the possibility of death and injury (Clifton \& Kreamer-Fults, 2007; LaScala, Johnson, \& Gruenewald, 2001). Therefore, planners need to understand not only the interrelationship between these factors, but also assess the risk of building environment during the planning, implementation and evaluation process. People who live communities with good transportation and pedestrian access tend to construe their communities as being safe (Hong \& Chen, 2014), thus demonstrating a potential indirect link between safety and the architectural environment (Loukaitou-Sideris, 2006; Wood et al., 2008).

The perceived change has to do with how humans receive information and stimulus from the physical environment through their five senses, and the mental process they go through to formulate evaluation, assessment, and interpretation based on past experience (Coeterier, 1987; Rapoport, 2016). Therefore, environmental transformation poses the most direct impact on perceived change. Based on the theory of evolution, it is human nature to feel attached to the environment (Riley, 1992). It is evident from the landscape assessment study that the types of the landscape may vary according to group preferences (Herzog, Herbert, Kaplan, \& Crooks, 2000; Strumse, 1996; Yu, 1995). Changes in the landscape or natural environment as a result of human activities also trigger different preferences among different groups, and people grow attached to specific places for various reasons (Low \& Altman, 1992; Toruńczyk Ruiz \& Lewicka, 2016).

Environmental changes are related to the changes in residents' place attachment. Among specific groups, such changes may affect people's sense of identity and generate strong place attachment. On the other hand, place attachment may also affect how people perceive changes in urban areas (Bonaiuto, Carrus, Martorella, \& Bonnes, 2002; Matilainen, Pohja-Mykrä, Lähdesmäki, \& Kurki, 2017). Therefore, before comprehending the influence of residents' attitudes and behavioral intentions, it is necessary to have a basic understanding of the relationship between characteristics of place changes and residents' attachment (von Wirth et al., 2016). Based on the above theory, it can be hypothesized that the planning and design of architectural environment have an impact on neighborhood security and it will affect residents' psychological state, thus affecting pedestrian behavior and attachment, as well as perception toward environmental changes. Therefore, this study hypothesizes that boundary removal project has an impact on perceived change, neighborhood safety, and place attachment.

\subsection{Materials and Methodology}

Based on the literature review, the relationships among BRP, perceived change, neighborhood safety, and place attachment could be identified. This study aims to explore the impact of BRP and the relationships among perceived change, neighborhood safety and place attachment.

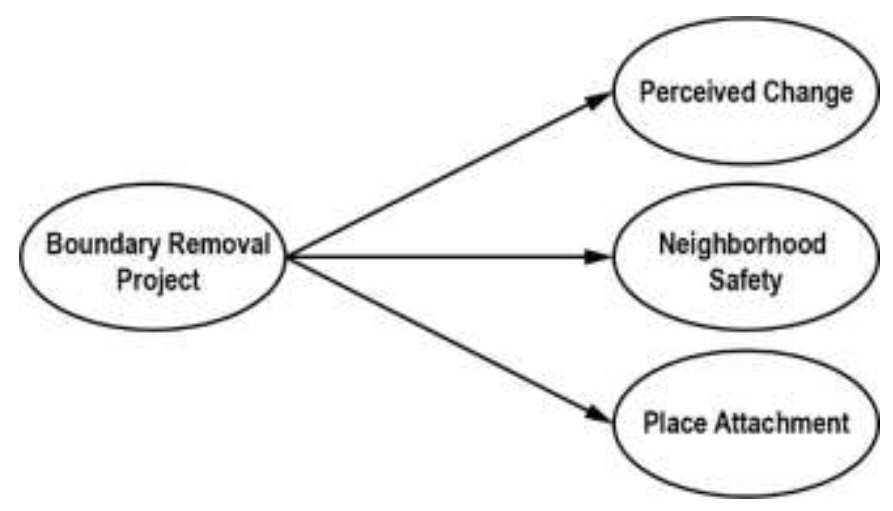

Fig. 1: Study framework 


\subsection{Study site}

This study has chosen three BRP cases in the Eastern District of Tainan as study sites. The scale of these cases and the degree of amelioration vary. They are Chong-Syue, Sheng-Li, and Da-Tong elementary schools.

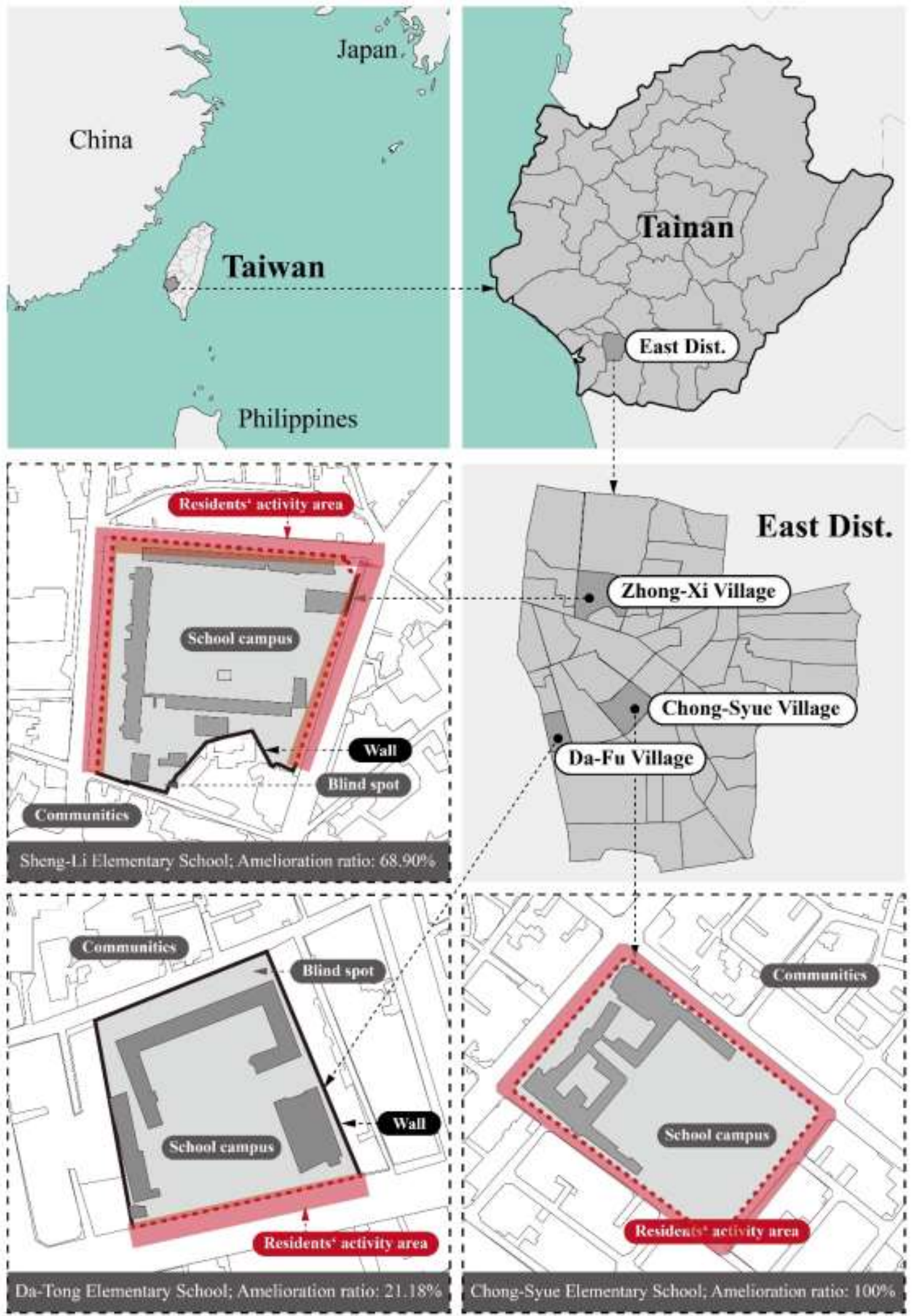

Fig. 2: Study sites 


\subsection{Population and Sampling}

The sample population of this study is residents within the 200-meter radius of the school campus. Based on the census information from Tainan City Government and the stratified-quota sampling method, the sample size should be 369 . The actual number of questionnaires distributed for each site was determined according to the percentage of the of each site against the combined population. A total of 431 questionnaires were collected and 392 are valid.

Table 1. The population of each study site

\begin{tabular}{lccccc}
\hline Elementary School & $\mathrm{N}$ & $\%$ & Questionnaire & Valid & Invalid \\
\hline Sheng-Li elementary school & 3,376 & $37.2 \%$ & 155 & 138 & 17 \\
\hline Chong-Syue elementary school & 3,766 & $41.5 \%$ & 175 & 161 & 14 \\
\hline Da-Tong elementary school & 1,935 & $21.3 \%$ & 101 & 93 & 8 \\
\hline \hline Total & 9,077 & $100 \%$ & 431 & 392 & 39 \\
\hline
\end{tabular}

\subsection{Measurement Scale}

Based on the literature review, the study proposes two sub-dimensions as the scale for perceived change. The sub-dimensions include "positive development" and "environmental change" (von Wirth, Grêt-Regamey, Moser, \& Stauffacher, 2016); the two sub-dimensions for neighborhood safety are "security against crime" and "traffic safety" (Saelens, Sallis, Black, \& Chen, 2003); the sub-dimensions for place attachment are "place identity" and "place dependence" (Anton \& Lawrence, 2016; Moore \& Graefe, 1994).

\subsection{Study method}

\subsubsection{Exploratory Factor Analysis}

The purpose of using factor analysis is to simplify data. In this study, factors with the same characteristics as BRP, perceived change, neighborhood safety, and place attachment were extracted. During the analysis, KMO sampling suitability test and Bartlett spherical test were conducted to determine whether the data is suitable for factor analysis. In addition, Cronbach's alpha is used to test the internal consistency of the latent dimensions (Hair, 2010).

\subsubsection{Multiple Regression Analysis}

Multiple regression analysis was conducted to explore the relationships between independent and dependent variables. Using the linear relationship between them, the prediction could be made to infer which independent variables affect the dependent variable. In this study, the multiple regression analysis is used to explore the relationships among BRP, perceived change, neighborhood safety, and place attachment.

\subsection{Results and discussion}

\subsection{Factors of boundary removal project (BRP)}

A01 to A29 are items included in BRP factors. First, reliability analysis is conducted, followed by factor analysis to consolidate and name the factors. Referencing past literature and the content under each factor, the six factors are named "directional system and public art", "planting", "outdoor furniture", "sidewalk", "lighting facilities" and "fence or hedge".

Table 2. Boundary removal project factor analysis

\begin{tabular}{llllllll}
\hline Item & Factor 1 & Factor 2 & Factor 3 & Factor 4 & Factor 5 & Factor 6 \\
\hline Directional system and public art (Factor 1) & & & & & & \\
\hline A18 & The design of directional signs is good. & .748 & .147 & .164 & .192 & .332 & .097 \\
A17 The content of directional signs is easy to read. & .721 & .148 & .201 & .172 & .314 & -.050 \\
A19 The directional signs are functional. & .705 & .226 & .241 & .175 & .343 & .097 \\
A21 The public art is approachable. & .674 & .298 & .216 & .201 & -.044 & .208 \\
A22 The placement of public art is appropriate. & .664 & .257 & .265 & .224 & .009 & .238 \\
A20 Each public art is distinct. & .632 & .283 & .148 & .164 & .031 & .371 \\
A23 The electricity poles or power distribution boxes have been & .523 & .210 & .092 & .060 & .189 & .258 \\
\hline & beautified. & & & & & & \\
\hline
\end{tabular}




\begin{tabular}{|c|c|c|c|c|c|c|c|}
\hline \multicolumn{8}{|c|}{ Planting (Factor 2) } \\
\hline A27 & Plants make me feel relaxed. & .239 & .811 & .115 & .209 & .147 & .148 \\
\hline A26 & One can see the green environment during the walk. . & .237 & .784 & .163 & .180 & .142 & .146 \\
\hline A29 & There is a variety of plants. & .158 & .742 & .194 & .146 & .227 & .065 \\
\hline A25 & The landscape design is unique. & .267 & .737 & .131 & .164 & .203 & .229 \\
\hline A28 & The plants are pleasing to the eye. & .214 & .736 & .110 & .124 & .171 & .152 \\
\hline \multicolumn{8}{|c|}{ Outdoor furniture (Factor 3 ) } \\
\hline A04 & The outdoor furniture is functional. & .141 & .152 & .830 & .084 & .071 & .185 \\
\hline A03 & The outdoor furniture blends with the surrounding. & .194 & .202 & .790 & .090 & .167 & .081 \\
\hline A01 & The location of outdoor furniture is appropriate. & .149 & .170 & .771 & .190 & .091 & .102 \\
\hline A05 & The outdoor furniture promotes interaction. & .175 & .130 & .770 & .151 & .040 & .120 \\
\hline $\mathrm{A} 02$ & The amount of outdoor furniture is adequate. & .166 & -.011 & .703 & .187 & .123 & .149 \\
\hline \multicolumn{8}{|c|}{ Sidewalk (Factor 4) } \\
\hline A06 & The sidewalk scale is appropriate. & .130 & .210 & .219 & .756 & .138 & .153 \\
\hline A08 & The sidewalks have good walkability. & .181 & .203 & .199 & .755 & .185 & .196 \\
\hline $\mathrm{A} 07$ & The sidewalks are barrier free. & .306 & .174 & .192 & .700 & .060 & .073 \\
\hline A09 & The pavement design is distinctive. & .279 & .237 & .179 & .536 & .218 & .344 \\
\hline \multicolumn{8}{|c|}{ Lighting facilities (Factor 5) } \\
\hline A14 & The lighting facilities provide adequate lighting. & .160 & .206 & .123 & .101 & .818 & .136 \\
\hline A15 & The lighting is soft. & .205 & .269 & .149 & .121 & .794 & .174 \\
\hline A16 & The lighting facilities blend with the surrounding environment. & .272 & .241 & .134 & .228 & .723 & .116 \\
\hline \multicolumn{8}{|c|}{ Fence or hedge (Factor 6 ) } \\
\hline A12 & The fence or hedge serves as a physical buffer. & .017 & .064 & .140 & .123 & .101 & .688 \\
\hline A11 & The fence or hedge is artistic. & .302 & .230 & .174 & .127 & .119 & .675 \\
\hline A13 & The fence or hedge are well designed. & .361 & .211 & .150 & .159 & .168 & .650 \\
\hline A10 & The fence or hedge is visually penetrable. & .203 & .270 & .329 & .243 & .094 & .465 \\
\hline \multicolumn{2}{|c|}{ Number of Item } & 7 & 5 & 5 & 4 & 3 & 4 \\
\hline \multicolumn{2}{|c|}{ Eigenvalue } & 11.975 & 2.180 & 1.468 & 1.415 & 1.223 & 1.084 \\
\hline \multicolumn{2}{|c|}{ Cronbach's a } & 0.898 & 0.910 & 0.886 & 0.834 & 0.877 & 0.754 \\
\hline \multicolumn{2}{|c|}{ Explained Variation (\%) } & 14.868 & 13.958 & 13.458 & 9.206 & 9.198 & 8.404 \\
\hline \multicolumn{2}{|c|}{ Total Explained Variation (\%) } & 14.868 & 28.826 & 42.284 & 51.490 & 60.687 & 69.092 \\
\hline
\end{tabular}

4.2 The total effect of BRP on perceived change, neighborhood safety, and place attachment

The results show that BRP has a significant effect on neighborhood safety, perceived change and place attachment, and all with a large effect size (Cohen, 1992). Ranking from large to small effect sizes are perception of environmental change, neighborhood safety and place attachment. Overall, planting has the greatest impact on perceived change, neighborhood safety and place attachment.

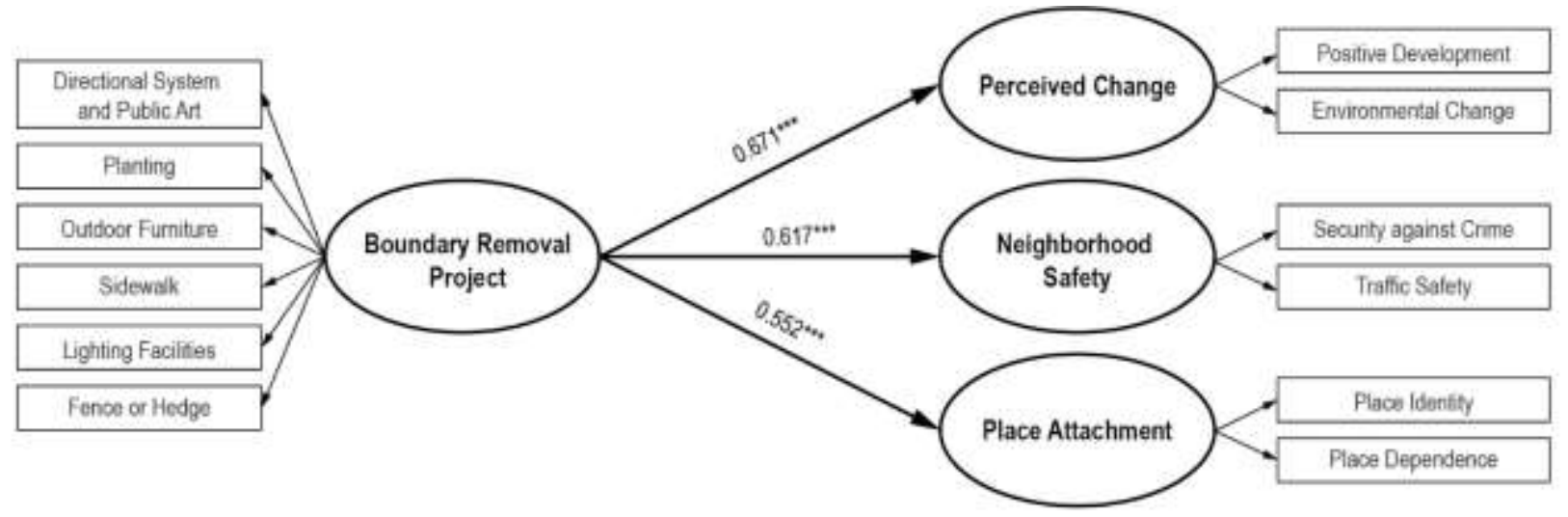

Fig. 3: The total effect of BRP on perceived change, neighborhood safety, and place attachment 


\subsection{The relationship between BRP elements and perceived change}

This study further explores the effect size of BRP factors on each dimension. The results are shown in Table 2. Among the BRP factors affecting perceived change, "planting", "outdoor furniture", "directional system and public art", "fence or hedge" and "lighting facilities" pose significant effects. Among them, "planting" is the most influential. The effect of planting reaches a medium size (0.36), and the effect size of other factors are small (0.1 0.16).

There are two factors in perceived change: positive development and environmental change. In the effect of BRP factors on positive development, only "planting", "outdoor furniture", "directional system and public art" and "fence or hedge" have significant effects. Among the factors, "planting" is the most influential (0.39). Therefore, the most effective way to enhance residents' perception of "positive development" is to strengthen planting.

In the effect of BRP factors on environmental change, only "planting", "directional system and public art", "outdoor furniture" and "lighting facilities" have a significant effect on positive development. Among them, "planting" has the most significant influence $(0.27)$. To factors of perceived change, fence or hedge contributes to positive development, and lighting facilities affect environmental change. To the perception of environmental, the sidewalk improvement is the only item that does not affect residents' perception.

Table 3. Perceived change affected by BRP factors, in which perceived change and its' factors regressed separately by six BRP factors.

\begin{tabular}{lllll}
\hline \multirow{2}{*}{ Dependent variable } & Independent variable & $\begin{array}{l}\text { Standardized } \\
\text { Coefficients } \\
\text { Beta }\end{array}$ & Sig. & VIF \\
& BRP elements & .355 & .000 & 1.954 \\
& Planting & .161 & .000 & 1.511 \\
& Outdoor furniture & .129 & .024 & 2.337 \\
& Directional system and public art & .106 & .037 & 1.880 \\
& Fence or hedge & .099 & .037 & 1.640 \\
\hline \hline
\end{tabular}

\begin{tabular}{lllll}
\hline \hline Factors of perceived change & & & & \\
& & & & \\
& & & \\
& Planting & .389 & .000 & 1.815 \\
Positive development & Outdoor furniture & .157 & .001 & 1.505 \\
& Directional system and public art & .133 & .019 & 2.175 \\
& Fence or hedge & .114 & .030 & 1.874 \\
\cline { 2 - 5 } & adjusted $\mathrm{R}^{2}=0.427$ & & $\mathrm{P}=0.030$ & \\
\hline \multirow{3}{*}{ Environmental change } & Planting & .267 & .000 & 1.860 \\
& Directional system and public art & .154 & .013 & 2.123 \\
& Outdoor furniture & .151 & .003 & 1.426 \\
& Lighting facilities & .109 & .046 & 1.634 \\
\cline { 2 - 5 } & adjusted $\mathrm{R}^{2}=0.297$ & & $\mathrm{P}=0.046$ & \\
\hline
\end{tabular}

The BRP factors have positive effects on perceived change. Planting is an important influence on visual preference and an important perceived factor, which is consistent with previous studies (Ode, Fry, Tveit, Messager, \& Miller, 2009; Purcell \& Lamb, 1998). In directional system and public art, as well as fence or hedge, well-designed artworks can inspire people and influence their perception (Denes, 1993). Therefore, artistic fences or artworks created with collaborate efforts from students improve people's perception of change.

\subsection{The relationship between BRP factors and neighborhood safety}

In the effect of BRP factors on neighborhood safety, "planting", "lighting facilities", "sidewalk", "outdoor furniture" and "fence or hedge" pose significant effects. Among them, "planting" is the most significant.

There are two factors in neighborhood safety: security against crime and traffic safety. In the effect of BRP factors on security against crime, only "fence or hedge", "directional system and public art" and "planting" have significant effects. The most influential is " fence or hedge". Prior to the BRP project, the fence and hedge create blind spots that became breeding ground for crimes. After the projects, the blind spots are eliminated, hence improving the sense of security against crime. 
In the effect on traffic safety, only "planting", "lighting facilities", "sidewalk" and "outdoor furniture" have significant effects. The most influential is "planting". It is important to note that lighting facilities do not help improve security against crime. Instead, this factor is helpful for traffic safety.

Table 4. Neighborhood safety affected by BRP factors, in which neighborhood safety and its' factors

\begin{tabular}{|c|c|c|c|c|}
\hline Dependent variable & $\begin{array}{l}\text { Independent variable } \\
\text { BRP elements }\end{array}$ & $\begin{array}{l}\text { Standardized } \\
\text { Coefficients } \\
\text { Beta }\end{array}$ & Sig. & VIF \\
\hline \multirow{6}{*}{ Neighborhood safety } & Planting & .215 & .000 & 1.883 \\
\hline & Lighting facilities & .171 & .001 & 1.575 \\
\hline & Sidewalk & .149 & .008 & 1.978 \\
\hline & Outdoor furniture & .135 & .006 & 1.522 \\
\hline & Fence or hedge & .121 & .028 & 1.861 \\
\hline & adjusted $R^{2}=0.374$ & & $\mathrm{P}=0.028$ & \\
\hline \multicolumn{5}{|c|}{ Factors of neighborhood safety } \\
\hline \multirow{4}{*}{ Security against crime } & Fence or hedge & .208 & .000 & 1.764 \\
\hline & Directional system and public art & .195 & .002 & 2.030 \\
\hline & Planting & .173 & .004 & 1.805 \\
\hline & adjusted $R^{2}=0.238$ & & $P=0.004$ & \\
\hline \multirow{5}{*}{ Traffic safety } & Planting & .231 & .000 & 1.766 \\
\hline & Lighting facilities & .207 & .000 & 1.562 \\
\hline & Sidewalk & .169 & .002 & 1.814 \\
\hline & Outdoor furniture & .160 & .001 & 1.436 \\
\hline & adjusted $R^{2}=0.361$ & & $P=0.001$ & \\
\hline
\end{tabular}

On the impact of BRP factors on neighborhood safety, when planting, lighting facilities, sidewalk, outdoor furniture, and other design elements are well planned, they positively affect the safety of a neighborhood and enhances traffic safety. In terms of planting, it has been verified that roadside vegetation has a positive psychological impact on drivers. It reduces their pressure and frustration when driving and reduces their driving speed as well as the risk of collision (Van Treese II, Koeser, Fitzpatrick, Olexa, \& Allen, 2017; Wolf, 2003). Lighting facilities will increase the visibility for both pedestrians and drivers and improve traffic safety. The design and maintenance of pedestrian walkways and outdoor furniture also affect pedestrian safety (Clifton and Kreamer-Fults, 2007). Fence or hedge, which defines the boundary, can protect the personal and property safety. The fence and hedge are lowered after the BRP project, which minimizes the blind spots, increase visibility, which greatly improves security against crime.

\subsection{The relationship between BRP factors and place attachment}

In the effect of BRP factors on place attachment, only " planting", "fence or hedge" and "outdoor furniture" have significant effects on place attachment. Among them, the most influential is " planting" (0.39). The other three design factors have no influence on place attachment.

There are two factors in place attachment: place identity and place dependence. The ranking of the effects of design factors on the two place attachment factors is the same. The most significant is planting. Therefore, the most effective way to increase place attachment is to improve the design of planting.

BRP factors also have a positive effect on place attachment. Residents are highly attached to the natural environment (Korpela, Ylén, Tyrväinen \& Silvennoinen, 2009; Muslim, 2016). Many environmental attributes are also critical for place attachment, while natural environment and social communication are more prominent (Kaltenborn \& Williams, 2002), so planting, which could be considered part of the natural environment, and outdoor furniture, which encourages social interaction, have an effect on place attachment. The higher the place attachment is for the local residents, the more they like the local landscape (Kaltenborn \& Bjerke, 2002). 
Table 5. Place attachment affected by BRP factors, in which place attachment and its' factors regressed separately by six BRP factors.

\begin{tabular}{lllll}
\hline \multirow{2}{*}{ Dependent variable } & Independent variable & $\begin{array}{l}\text { Standardized } \\
\text { Coefficients }\end{array}$ & Sig. & VIF \\
& BRP elements & Beta & & \\
\hline \multirow{3}{*}{ Place attachment } & Planting & .394 & .000 & 1.515 \\
& Fence or hedge & .155 & .004 & 1.669 \\
& Outdoor furniture & .125 & .012 & 1.405 \\
\cline { 2 - 5 } & adjusted $\mathrm{R}^{2}=0.463$ & & $\mathrm{P}=0.037$ & \\
\hline \hline \multirow{2}{*}{ Factors of place attachment } & & & & \\
& Planting & .388 & .000 & 1.515 \\
& Fence or hedge & .131 & .018 & 1.669 \\
& Outdoor furniture & .120 & .018 & 1.405 \\
\cline { 2 - 5 } & adjusted $\mathrm{R}^{2}=0.290$ & & $\mathrm{P}=0.018$ & \\
\hline \multirow{3}{*}{ Place dependence } & Planting & .372 & .000 & 1.515 \\
& Fence or hedge & .166 & .002 & 1.669 \\
& Outdoor furniture & .122 & .015 & 1.405 \\
\cline { 2 - 5 } & adjusted $\mathrm{R}^{2}=0.304$ & & $\mathrm{P}=0.015$ & \\
\hline
\end{tabular}

\subsection{Scope of impact for the six BRP factors}

The six design factors of the BRP impact the sub-dimensions of the residents' perceptions differently. Among the factors, planting is the strongest and most influential, followed by outdoor furniture, and then by fence or hedge (Table 5). Designers and planners should utilize the three design factors to enhance the effects of environmental amelioration. In addition, directional system and public arts contribute specifically toward the perception of changing, such as positive development and environmental change.

Table 6. Scope of impact of the six design elements on boundary removal project

\begin{tabular}{|c|c|c|c|c|c|c|}
\hline & \multicolumn{2}{|c|}{ Perceived change } & \multicolumn{2}{|c|}{ Neighborhood safety } & \multicolumn{2}{|c|}{ Place attachment } \\
\hline & $\begin{array}{l}\text { Positive } \\
\text { development }\end{array}$ & $\begin{array}{l}\text { Environmental } \\
\text { change }\end{array}$ & $\begin{array}{l}\text { Security against } \\
\text { crime }\end{array}$ & Traffic safety & Place identity & $\begin{array}{l}\text { Place } \\
\text { dependence }\end{array}$ \\
\hline Directional system and public arts & O & $\mathrm{O}$ & $\bigcirc$ & & & \\
\hline Planting & (0) & ○ & O & $\bigcirc$ & () & () \\
\hline Outdoor furniture & $\bigcirc$ & O & & $\bigcirc$ & O & $\bigcirc$ \\
\hline Sidewalk & & & & $\bigcirc$ & & \\
\hline Lighting facilities & & $\bigcirc$ & & $\bigcirc$ & & \\
\hline Fence or hedge & 0 & & 0 & & O & $\bigcirc$ \\
\hline
\end{tabular}

\footnotetext{
O: with a significant impact

() : effect size of the impact greater than 3.0 (medium)
}

\subsection{Limitation}

This study is a cross-sectional investigation, in which the directions of causal inferences are based on literature and theories. Due to financial limitations, only three elementary schools in Tainan were chosen as the study sites for this study. The sample size satisfies the statistical analyses. The result of factor analysis is based on sampling, and different sample site will lead to different result. This study took Taiwan as a study site, the factor of BRP will be different from those in other countries.

\subsection{Conclusion}

The results of this study show that the boundary removal project has a significant impact on perceived change, neighborhood safety and place attachment for community residents, and all with a large effect size. Upon further study on the effects of various spatial modification factors on the three dimensions, it is revealed that "planting" has the greatest impact on the three dimensions, especially on place attachment (0.39), followed by perception of environmental change (0.36). Except for security against crime, planting has the greatest impact on the other five environmental design factors. 
Among the elements, planting is the strongest and most influential, followed by outdoor furniture, and then by fence or hedge. Designers and planners should take full advantage of these three design elements to amplify the effect of environmental amelioration. To enhance residents' perception of "positive development", the most effective way is to enhance the planting. Directional systems and public arts especially contribute to the perception of change. Fence or hedge, directional systems, and public arts, and planting are three design factors that have a significant impact on security against crime. To strengthen place attachment, an effective approach is to strengthen planting and vegetation. This study may help designers and planners achieve the desired effects.

\section{Acknowledgments}

This research was funded by a grant from the Ministry of Science and Technology Taiwan with the project number: MOST-105-2511-S006-014

\section{References}

Anton, C. E., \& Lawrence, C. (2016). The relationship between place attachment, the theory of planned behaviour and residents' response to place change. Journal of Environmental Psychology, 47, 145-154.

Bonaiuto, M., Carrus, G., Martorella, H., \& Bonnes, M. (2002). Local identity processes and environmental attitudes in land use changes: The case of natural protected areas. Journal of economic psychology, 23(5), 631-653.

Clifton, K. J., \& Kreamer-Fults, K. (2007). An examination of the environmental attributes associated with pedestrian-vehicular crashes near public schools. Accident Analysis \& Prevention, 39(4), 708-715.

Coeterier, J. F. (1987). De waarneming en waardering van landschappen. Coeterier.

Cohen, J. (1992). A power primer. Psychological bulletin, 112(1), 155.

Daniel, T. C., \& Vining, J. (1983). Methodological issues in the assessment of landscape quality Behavior and the natural environment (pp. 39-84): Springer.

Denes, A. (1993). Notes on eco-logic: Environmental artwork, visual philosophy and global perspective. Leonardo, 387-395.

Hair, J. F. (2010). Black, WC, Babin, BJ, \& Anderson, RE (2010). Multivariate data analysis, 7.

Herzog, T. R., Herbert, E. J., Kaplan, R., \& Crooks, C. (2000). Cultural and developmental comparisons of landscape perceptions and preferences. Environment and Behavior, 32(3), 323-346.

Hong, J., \& Chen, C. (2014). The role of the built environment on perceived safety from crime and walking: examining direct and indirect impacts. Transportation, 41(6), $1171-1185$.

Kaltenborn, B. P., \& Bjerke, T. (2002). Associations between landscape preferences and place attachment: a study in Røros, Southern Norway. Landscape Research 27(4), 381-396.

Kaltenborn, B. P., \& Williams, D. R. (2002). The meaning of place: Attachments to Femundsmarka National Park, Norway, among tourists and locals. Norsk Geografisk Tidsskrift, 56(3), 189-198.

Korpela, K. M., Ylén, M., Tyrväinen, L., \& Silvennoinen, H. (2009). Stability of self-reported favourite places and place attachment over a 10-month period. Journal of Environmental Psychology, 29(1), 95-100.

LaScala, E. A., Johnson, F. W., \& Gruenewald, P. J. (2001). Neighborhood characteristics of alcohol-related pedestrian injury collisions: a geostatistical analysis. Prevention Science, 2(2), 123-134

Lau, S. S. Y., Gou, Z., \& Liu, Y. (2014). Healthy campus by open space design: Approaches and guidelines. Frontiers of Architectural Research, 3(4), $452-467$.

Low, S. M., \& Altman, I. (1992). Place attachment Place attachment (pp. 1-12): Springer.

Lynch, K., \& Hack, G. (1984). Site planning: MIT press.

Matilainen, A., Pohja-Mykrä, M., Lähdesmäki, M., \& Kurki, S. (2017). "I feel it is mine!"-Psychological ownership in relation to natural resources. Journal of Environmental Psychology, 51, 31-45.

Mehta, V. (2014). Evaluating public space. Journal of Urban Design, 19(1), 53-88.

Moore, R. L., \& Graefe, A. R. (1994). Attachments to recreation settings: The case of rail-trail users. Leisure sciences, 16(1), $17-31$.

Muslim, Z. (2016). Design Transformation based on Nature and Identity Formation in the Design of Landscape Elements. Environment-Behaviour Proceedings Journal, 1(1), 189-196

Ode, Å., Fry, G., Tveit, M. S., Messager, P., \& Miller, D. (2009). Indicators of perceived naturalness as drivers of landscape preference. Journal of Environmental Management, 90(1), 375-383.

Omar, D., Omar, K. A., Othman, S., \& Yusoff, Z. M. (2016). Walkability design for urban public housing park. Environment-Behaviour Proceedings Journal, 1(3), 311-317. 
Purcell, A. T., \& Lamb, R. J. (1998). Preference and naturalness: An ecological approach. Landscape and Urban Planning, 42(1), 57-66.

Rapoport, A. (2016). Human aspects of urban form: towards a man-environment approach to urban form and design: Elsevier.

Riley, R. B. (1992). Attachment to the ordinary landscape Place attachment (pp. 13-35): Springer.

Ruihai, Z., \& Dinghai, Y. (2017). Analysis and reform strategies of campus landscape of Hainan University. Journal of Landscape Research, 9(2), 23.

Saeidi, S., Mohammadzadeh, M., Salmanmahiny, A., \& Mirkarimi, S. H. (2017). Performance evaluation of multiple methods for landscape aesthetic suitability mapping: A comparative study between Multi-Criteria Evaluation, Logistic Regression and Multi-Layer Perceptron neural network. Land Use Policy, 67, 1-12.

Saelens, B. E., Sallis, J. F., Black, J. B., \& Chen, D. (2003). Neighborhood-based differences in physical activity: an environment scale evaluation. American journal of public health, 93(9), 1552-1558.

Strumse, E. (1996). Demographic differences in the visual preferences for agrarian landscapes in western Norway. Journal of Environmental Psychology, 16(1), 17-31.

Sullivan, W. C., Kuo, F. E., \& Depooter, S. F. (2004). The fruit of urban nature: Vital neighborhood spaces. Environment and Behavior, 36(5), 678-700.

Toruńczyk-Ruiz, S., \& Lewicka, M. (2016). Perceived social diversity and neighbourhood attachment: The role of intergroup ties and affective appraisals of the environment. Evidence from Poland. European Journal of Social Psychology, 46(7), 818-832.

Van Treese II, J. W., Koeser, A. K., Fitzpatrick, G. E., Olexa, M. T., \& Allen, E. J. (2017). A review of the impact of roadway vegetation on drivers' health and well-being and the risks associated with single-vehicle crashes. Arboricultural Journal, 39(3), 179-193.

von Wirth, T., Grêt-Regamey, A., Moser, C., \& Stauffacher, M. (2016). Exploring the influence of perceived urban change on residents' place attachment. Journal of Environmental Psychology, 46, 67-82.

Williams, D. R., \& Roggenbuck, J. W. (1989). Measuring place attachment: Some preliminary results. Paper presented at the Abstracts: 1989 leisure research symposium.

Wolf, K. L. (2003). Freeway roadside management: the urban forest beyond the white line. Journal of Arboriculture, 29(3), 127-136.

Wood, L., Shannon, T., Bulsara, M., Pikora, T., McCormack, G., \& Giles-Corti, B. (2008). The anatomy of the safe and social suburb: an exploratory study of the built environment, social capital and residents' perceptions of safety. Health \& place, 14(1), 15-31.

Yu, K. (1995). Cultural variations in landscape preference: comparisons among Chinese sub-groups and Western design experts. Landscape and Urban Planning, 32(2), 107-126.

Zhang, H., \& Lin, S.-H. (2011). Affective appraisal of residents and visual elements in the neighborhood: A case study in an established suburban community. Landscape and Urban Planning, 101(1), 11-21. 